\title{
Considerações sobre o tédio em Schopenhauer e Fernando Pessoa: convergências e dissonâncias
}

\section{Considerations about the boredom in Schopenhauer and Fernando Pessoa: convergences and dissonances}

\section{Leandro Chevitarese}

Professor Adjunto de Filosofia do Departamento de Educação e Sociedade IM/UFRRJ e do Programa de Pós-Graduação em Filosofia da UFRRJ. Membro do Núcleo de Estudos Schopenhauer-Nietzsche da UFRRJ e integrante do Núcleo de Sustentação do GT

Schopenhauer da ANPOF

E-mail: leandrochevitarese@yahoo.com.br

Resumo: O presente artigo pretende investigar algumas convergências e dissonâncias acerca do conceito de "tédio" em Schopenhauer e na obra Livro do Desassossego, por Bernardo Soares, Fernando Pessoa.

Palavras-chave: Tédio; Desassossego; Fernando Pessoa.

Abstract: This article investigates some convergences and dissonances of the concept of "boredom" in Schopenhauer's work and in the Book of Disquiet, by Bernardo Soares, Fernando Pessoa.

Key words: Boredom; Disquiet; Fernando Pessoa.

A decifração metafísica empreendida por Schopenhauer nos revela que, por sua constituição essencial, a vida é sofrimento. Para o filósofo, isto significa que a dinâmica da vida oscila entre a dor e o tédio, seus componentes fundamentais. Fernando Pessoa, por sua vez, não oferece tanta centralidade à questão do tédio em suas obras. Todavia, há uma interessante análise desenvolvida pelo autor sobre o tema, particularmente no Livro do Desassossego, por Bernardo Soares. Sendo assim, a partir da apresentação de alguns elementos centrais para a compreensão do "tédio" [Langeweile] em Schopenhauer, o presente artigo pretende tecer considerações acerca de sua convergência e dissonância com o entendimento que se desenvolve nesta obra de Pessoa $^{1}$. Mas o leitor não encontrará aqui uma pesquisa acabada sobre a articulação

\footnotetext{
${ }^{1}$ Cabe ressaltar que não se pretende aqui, de modo algum, uma análise de conjunto da obra de Fernando Pessoa, nem muito menos afirmar uma "influência" direta da obra do filósofo sobre o escritor. Objetivase apenas tecer algumas considerações acerca do contraste de tais formulações sobre o "tédio". Além
} 


\section{LEANDRO CHEVITARESE}

deste conceito nos dois autores - tem-se no máximo a apresentação de uma hipótese de trabalho. Trata-se, na verdade, de uma provocação filosófica e poética para os interessados nesta temática.

\section{Considerações sobre Schopenhauer e o tédio}

Conceber a vontade como essência de todas as coisas implica na construção de uma visão de mundo em que o sofrimento é condição existencial. Schopenhauer afirma que a vontade, em todas as suas formas de manifestação, é ausente de qualquer finalidade última, pois apenas o esforço lhe é essencial. Tal ímpeto não cessa quando se atinge um determinado alvo. Incapaz de uma satisfação última, a vontade se desdobra em outras direções, retardando-se apenas diante dos empecilhos que se interpõem, multiplicando as formas de sofrimento. Cabe ainda enfatizar: para o filósofo o próprio esforço - que na condição humana manifesta-se como desejo - já constitui sofrimento:

Todo esforço nasce da carência, do descontentamento com o próprio estado e é, portanto, sofrimento pelo tempo que não é satisfeito; nenhuma satisfação, todavia, é duradoura, mas antes é sempre um ponto de partida para um novo esforço, o qual, por sua vez, vemos travado em toda parte de diferentes maneiras, em toda parte lutando, e assim, portanto, sempre como sofrimento: não há nenhum fim último do esforço, portanto não há nenhuma medida e fim do sofrimento ${ }^{2}$.

Pode-se dizer que "toda a vida é sofrimento" (alles Leben Leiden ist) ${ }^{3}$, mas não no sentido de que sofremos "o tempo todo da vida", porém no sentido de que em nossa essência encontra-se uma vontade cega, faminta e insaciável. Embora presente em toda a manifestação, é no homem que o sofrimento atinge o mais alto grau, devido à sua consciência e conhecimento abstrato. Mesmo se a vontade, arrebatada ao júbilo e felicidade momentâneos, tornar-se ausente de objeto, ou seja, se uma satisfação, ainda que efêmera, roubar-lhe todo o motivo e querer, há o mergulho em um insuportável

disso, vale ainda registrar que, no caso de Fernando Pessoa, a análise se concentrará exclusivamente no Livro do Desassossego, por Bernardo Soares.

${ }^{2}$ SCHOPENHAUER, MVR I, § 56, p.399.

${ }^{3}$ SCHOPENHAUER, MVR I, § 57, p.400. 
tédio e vazio. Sendo assim, a "vida, portanto, oscila como um pêndulo, para aqui e para acolá, entre a dor e o tédio, os quais em realidade são seus componentes básicos"4.

Buscamos a "libertação" do sofrimento pela incompreensão de que o sofrer, nas suas mais variadas manifestações fenomênicas, é implícito à essência do viver. Deste modo, o filósofo acaba por conceber a satisfação, a felicidade, como algo negativo, ou seja, que só podemos conhecer por contraste, indiretamente pela cessação de um desejo, de uma privação (condição prévia de todo o prazer). Alcançando-se o objeto do desejo, termina a dor que o acompanhava, mas, por conseguinte, também o prazer, efêmera sensação da realização momentânea do querer. Surge então um novo desejo, ou aprofunda-se o estado de espera sem objeto, o peso do tédio.

Portanto, entre querer e alcançar, flui sem cessar toda a vida humana. O desejo, por sua própria natureza, é dor; já a satisfação logo provoca saciedade; o fim fora apenas aparente; a posse elimina a excitação, porém o desejo, a necessidade aparece em nova figura; quando não, segue-o o langor, o vazio, o tédio, contra os quais a luta é tão atormentadora quanto contra a necessidade ${ }^{5}$.

Em Aforismos para sabedoria de vida, Schopenhauer concebe aquilo que poderia ser considerado como "felicidade" como um estado de ausência da dor e do tédio: "se a um estado sem dor ainda couber a ausência de tédio, então a felicidade terrena foi em essência alcançada; o resto é quimera" ${ }^{\circ}$. Nesta obra encontra-se uma investigação acerca destes dois principais "inimigos da felicidade”.

É interessante observar que tanto na exterioridade, quanto na interioridade, a dor e o tédio permanecem em uma relação antagônica. Do ponto de vista exterior, enquanto "a privação e a necessidade geram dor; em contrapartida, a segurança e a abundância geram o tédio", . Aquele que "menos tem" exteriormente convive diariamente com a falta e a carência, que tornam sua vida, a maior parte do tempo, dedicada a aliviar suas necessidades mais imediatas. Por outro lado, aquele que "mais tem" exteriormente, torna-se vítima fácil do tédio. Já o antagonismo interior revela-se pelo fato de que "a suscetibilidade para um encontra-se em proporção inversa à suscetibilidade para o outro,

\footnotetext{
${ }^{4}$ SCHOPENHAUER, MVR I, § 57, p.402.

${ }^{5}$ SCHOPENHAUER, MVR I, § 57, p. 404.

${ }^{6}$ SCHOPENHAUER, ASV, p. 142 .

${ }^{7}$ SCHOPENHAUER, ASV, p.24.
} 


\section{LEANDRO CHEVITARESE}

já que ela é determinada pela medida de suas forças espirituais". Aquele que "menos tem" interiormente, sendo vítima de uma "vacuidade interior", torna-se muito mais suscetível ao tédio, que se encontra na raiz das distrações vulgares da sociabilidade. Por outro lado, aquele que "mais tem" interiormente, ou seja, aquele que é rico espiritualmente possui viva inteligência e intensa sensibilidade interior, dificilmente é presa do tédio, ainda que se torne mais suscetível a sofrer diante de mudanças e adversidades.

Em função desse antagonismo, Schopenhauer entende que um homem rico interiormente, por sua inteligência, buscará uma vida tranquila, preferindo a serenidade do ócio ao conflituoso contato humano, ou seja, preferirá muito mais se retirar da vida social, "pois é na solidão, onde cada um está entregue a si mesmo, que se mostra o que ele tem em si mesmo"9. Inversamente, para a maioria dos homens, a solidão, bem como a ausência de afazeres práticos, ou seja, o ócio, é uma escancarada porta de entrada para o tédio. Isso demonstra como o ócio per se é destituído de valor, pois tudo depende do modo como é experimentado: "as pessoas comuns estão preocupadas apenas em passar o tempo; quem possui algum talento, apenas em empregar o tempo" ${ }^{10}$. Para a tarefa de suportar o tempo surgem os mais diversos entretenimentos sociais, uma válvula de escape para a vacuidade interior. Mas todas as fontes externas de felicidade são por demais fugazes e precárias, submetidas à transitoriedade e marcadas pela insegurança.

Pode-se considerar que o tédio, polo oposto à dor na dinâmica do "pêndulo do sofrimento", apresenta no mínimo o mesmo grau de importância da dor sentida positivamente pela não realização de um desejo. Mas em geral não damos tanta atenção a tal problemática em nossas análises acerca da obra de Schopenhauer. Sem dúvida uma valiosa exceção é Didier Raymond, que dedica boa parte de seu livro ao tema. Para o autor, o tédio, mais do que uma questão central no pensamento do filósofo de Frankfurt, poderia mesmo ser tomado como "o problema específico da filosofia segundo Schopenhauer"11. Ainda que controversa, tal interpretação original destaca não somente a importância da problemática do tédio em Schopenhauer, mas também nos convida a

\footnotetext{
${ }^{8}$ SCHOPENHAUER, ASV, p.24.

${ }^{9}$ SCHOPENHAUER, ASV, p. 26.

${ }^{10}$ SCHOPENHAUER, ASV, p.28.

${ }^{11}$ RAYMOND, Schopenhauer. Écrivains de toujours, p.116. 
pensar sobre a possibilidade de redimensionar o tema, integrando-o no conjunto dos grandes problemas filosóficos do pensamento ocidental.

A partir desta breve contextualização, vejamos alguns fragmentos de Fernando Pessoa sobre o "tédio", em contraste com a filosofia de Schopenhauer.

\section{Fernando Pessoa e o tédio: convergências e dissonâncias com Schopenhauer}

No Livro do Desassossego, Pessoa nos oferece uma interessante análise sobre o tédio, particularmente na seção intitulada Milímetros (sensações das coisas mínimas). Nas palavras de Bernardo Soares: "tão dado que sou ao tédio, é curioso que nunca, até hoje, me lembrou em meditar em que consiste. Estou hoje, deveras, nesse estado intermédio da alma em que nem apetece a vida nem outra coisa" ${ }^{\prime 2}$. Assim floresce sua leitura sobre este estado da alma, no qual o desprazer pela vida se torna presente sem que nada se ofereça como alternativa. Uma condição que não respeita normas para seu aparecimento: há domingos inertes em que não surge, ainda que se possa tê-lo presente em dia de pleno trabalho. Afirmá-lo como uma "angústia metafísica disfarçada", ou “desilusão incógnita", ou "poesia surda da alma aflorando aborrecida" nada mais é do que colorir o tédio sem trazê-lo à superfície. O tédio parece exigir de Bernardo Soares um pouco de desnudamento de sua própria alma:

O tédio... Pensar sem que se pense, com o cansaço de pensar; sentir sem que se sinta, com a angústia de sentir, não querer sem que se não queira, com a náusea de não querer. (...) O tédio... Sofrer sem sofrimento, querer sem vontade, pensar sem raciocínio... É como a possessão por um demônio negativo, um embruxamento por coisa nenhuma ${ }^{13}$.

Mas o autor adverte: "tudo isto está no tédio sem ser o tédio", trata-se de algo que emerge dele ainda que não lhe constitua fundamentalmente. Pois ainda, o tédio "é uma sensação de vácuo, uma fome sem vontade de comer, tão nobre como estas

\footnotetext{
12 PESSOA, Livro do Desassossego, p.194.

${ }^{13}$ PESSOA, Livro do Desassossego, p.195. 


\section{LEANDRO CHEVITARESE}

sensações do simples cérebro, do simples estômago, vindas de fumar demais ou de não digerir bem"14.

A partir desta "sensação de vacuidade", que parece ser própria ao tédio, torna-se interessante observar a convergência com a filosofia de Schopenhauer, que pode ser bem observada na remissão aos "Suplementos à Doutrina da Nulidade da Existência", presente em Parerga e Paralipomena:

Que mesmo por detrás da miséria encontramos o tédio, que acomete até mesmo os animais mais inteligentes, é uma consequência do fato de que a vida não tem nenhum conteúdo verdadeiro e genuíno, mas se mantém em movimento apenas através da carência e da ilusão: tão logo isso cessa, torna-se evidente a completa pobreza e o vazio da existência. (...) A existência em si mesma não tem nenhum valor, pois o tédio nada mais é que o sentimento de sua vacuidade ${ }^{15}$.

O tédio como experiência do vazio da existência. Experiência do absurdo de existir em mundo destituído de valor, mundo suspenso no incomensurável abismo do nada. Ao que tudo indica, podemos observar aqui uma significativa aproximação na análise promovida pelos dois autores acerca do tédio. É o mesmo que se pode observar em relação à busca de construções metafísicas e crenças como forma de aliviar ou fugir do tédio.

O tédio... é talvez, no fundo, a insatisfação da alma por não lhe termos dado uma crença, a desolação da criança triste que intimamente somos, por não lhe termos comprado o brinquedo divino. É talvez a insegurança de quem precisa mão que o guie, e não sente, no caminho negro da sensação profunda, mais que a noite sem ruído de não poder pensar, a estrada sem nada de não saber sentir. (...) Quem tem Deuses nunca tem tédio. O tédio é a falta de uma mitologia ${ }^{16}$.

Para Bernardo Soares, o tédio é um estado que aflige àqueles que se tornaram incapazes de construir para si mesmos o refúgio da crença, que não conseguem mais mergulhar no encantamento de qualquer mitologia. Por isso assevera: "Sim, o tédio é isso: a perda, pela alma, da sua capacidade de se iludir, a falta, no pensamento, da

\footnotetext{
${ }^{14}$ PESSOA, Livro do Desassossego, p.196.

${ }^{15}$ SCHOPENHAUER, P/P, § 146, pp.141-142.

${ }^{16}$ PESSOA, Livro do Desassossego, p.196. 
escada inexistente por onde ele sobe sólido à verdade" ${ }^{\text {17 }}$. O tédio revela $\mathrm{o}$ desmantelamento de todos os caminhos seguros da existência. Uma desorientação persistente advinda da lacuna gerada pela desilusão quanto à verdade. Experiência de reconhecer-se sob um abismo dilacerante, que surge onde antes havia apenas solidez. Um sentimento de perda de todos os referentes, "um sentimento de desolação sem lugar, de naufrágio de toda a alma" ${ }^{\prime 18}$.

Schopenhauer também relaciona o tédio à construção de metafísicas religiosas, mas sua formulação apresenta distinções. Trata-se aqui de algo que pode ser considerado como uma convergência, mas cabe destacar as diferenças de formulação do problema - ainda que se possa supor que ambos os autores pretendam o mesmo. Mas para o filósofo, não seria o caso de afirmar que "Quem tem Deuses nunca tem tédio", melhor seria: por que há tédio é que se criam deuses. Como efeito da condição ontológica que nos é própria, não há quem escape ao tédio, mas o sofrimento por ele gerado é a raiz não somente de toda sorte de entretenimentos, como também da criação de mitologias e superstições.

No entanto, por mais que grandes e pequenas vicissitudes preencham qualquer vida humana e sempre a mantenham em constante desassossego e excitação, não conseguem esconder a inadequação da vida em satisfazer o espírito, nem escondem o vazio e a superficialidade da existência, muito menos o tédio que sempre está preparado para ocupar qualquer espaço deixado livre pela preocupação. Daí advém que o espírito humano, não contente o bastante com as preocupações, ansiedades e cuidados que lhe são postos pelo mundo real, criou ainda para si um mundo imaginário na figura de milhares de superstições, as mais variadas, ocupando-se com ele das mais diferentes maneiras, dispendendo desse modo tempo e força tão logo o mundo real the concede repouso (...) ${ }^{19}$.

De fato, o vazio da existência e o tédio são fatores geradores de toda trama das metafísicas religiosas. Schopenhauer reconhece que há uma Necessidade Metafísica da Humanidade que emerge a partir da consciência da morte, da finitude de toda a existência, que nos "impõe em maior ou menor grau a inutilidade de todos os nossos

\footnotetext{
${ }^{17}$ PESSOA, Livro do Desassossego, p.196

${ }^{18}$ PESSOA, Livro do Desassossego, p.197.

${ }^{19}$ SCHOPENHAUER, MVR I, § 58, p.415.
} 


\section{LEANDRO CHEVITARESE}

esforços" ${ }^{20}$. Mas sua filosofia quer atender tal necessidade sem recorrer ao subterfúgio das mitologias e superstições. Por isso, sua Metafísica "permanece imanente, e não se torna transcendente, pois nunca se subtrai da experiência, mas pelo contrário, continua a ser uma simples interpretação e explicação da mesma" ${ }^{\text {21 }}$.

Entretanto, Schopenhauer relaciona a construção de sistemas religiosos e superstições também a uma demanda humana por entretenimento, uma forma de escapar ao tédio: "Trata-se aí da expressão, do sintoma relacionado à dupla necessidade

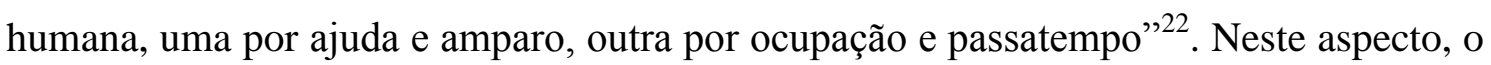
filósofo parece apresentar uma dissonância em relação ao escritor: o tédio não se relaciona somente com as crenças religiosas, mas também é a raiz de todas as diversões e entretenimentos sociais.

Para o filósofo, o impulso à sociabilidade se funda no temor à solidão, ou seja, o medo desesperado de vivenciar o tédio. Buscamos o convívio social como forma de escaparmos de nós mesmos, ou simplesmente, para fugirmos do tédio. A sociabilidade é uma válvula de escape diante de nossa dificuldade de suportar o que somos. O medo e a repulsa da solidão são o temor e a aversão que cada um tem de si mesmo. "Vazio interior e fastio: eis o que os impele tanto para a sociedade quanto para os lugares exóticos e as viagens" ${ }^{23}$.

Parece inevitável lembrar aqui da mais famosa alegoria criada por Schopenhauer: a "fábula dos porcos-espinhos" 24 . Se, por um lado, é insuportável para esta vara de porcos-espinhos recém-nascidos suportar o frio, é também extremamente dolorosa a aproximação entre eles. Se o tédio, o vazio, o frio, conduz-nos à sociabilidade; a convivência humana, por sua vez, traz consigo nova carga de sofrimentos. Por fim, não devemos esquecer que Schopenhauer formula tal alegoria para elogiar aqueles que possuem Gênio, difíceis presas do tédio, pois tem "calor" suficiente em si mesmos para abraçar a solidão como uma dádiva. Todavia, para o homem comum permanece o eterno "pêndulo do sofrimento", entre a dor e o tédio.

\footnotetext{
${ }^{20}$ SCHOPENHAUER, MVR II, Cap. XVII, Vol.1, p.249.

${ }^{21}$ SCHOPENHAUER, MVR II, Cap. XVII, Vol.1, p.279.

${ }^{22}$ SCHOPENHAUER, MVR I, § 58, p.416.

${ }^{23}$ SCHOPENHAUER, ASV, p. 165.

${ }^{24}$ SCHOPENHAUER, P/P, § 396, Vol. II, pp.651-652.
} 
Bernardo Soares, a seu modo, procura também aprofundar a leitura sobre o tédio, procurando distingui-lo e relacioná-lo com outras afecções, como o cansaço, o mal-estar e o aborrecimento, que participam do tédio como seus componentes, do mesmo modo que o hidrogênio e o oxigênio participam da água. Entretanto, a composição daí resultante traz uma singularidade que não se pode deixar de destacar:

O tédio é, sim, o aborrecimento do mundo, o mal-estar de estar vivendo, o cansaço de se ter vivido; o tédio é, deveras, a sensação carnal da vacuidade prolixa das coisas. Mas o tédio é, mais do que isto, o aborrecimento de outros mundos, quer existam quer não; o malestar de ter que viver, ainda que outro, ainda que de outro modo, ainda que noutro mundo; o cansaço, não só de ontem e de hoje, mas de amanhã também, (e) da eternidade, se a houver, (e) do nada, se é ele que é a eternidade. Nem é só a vacuidade das coisas e dos seres que dói na alma quando ela está em tédio: é também a vacuidade de outra coisa qualquer, que não as coisas e os seres, a vacuidade da própria alma que sente o vácuo, que se sente vácuo, e que nele de si se enoja e se repudia ${ }^{25}$.

O sofrimento como condição existencial, e particularmente a experiência do tédio, pode nos levar a compreensão da impossibilidade de escapar de tal condição de vacuidade. Tem-se então uma presentificação do "horror de viver". Como Bernardo Soares nos diz:

É tão magno o tédio, tão soberano o horror de estar vivo que não concebo que coisa haja que pudesse servir de lenitivo, de antídoto, de bálsamo ou esquecimento para ele. Dormir horroriza-me como tudo. Morrer horroriza-me como tudo. Ir e parar são a mesma coisa impossível. Esperar e descrer equivalem-se em frio e cinza. Sou uma prateleira de frascos vazios ${ }^{26}$.

Trata-se de uma impossibilidade de viver diante da constatação de todo vazio da existência que se revela no tédio. Parece convidativo lembrar aqui da formulação de Schopenhauer acerca da vida como uma "mercadoria ruim", ou de sua ênfase na vida não como um presente, mas sim como problema que nos exige algum tipo de enfrentamento. É o que se pode observar em "Sobre a Nulidade e o Sofrimento da

\footnotetext{
${ }^{25}$ PESSOA, Livro do Desassossego, p.203.

${ }^{26}$ PESSOA, Livro do Desassossego, p.197, meus grifos.
} 
Vida", que faz parte dos Complementos a $O$ Mundo como Vontade e como Representação:

Se a vida em si fosse uma benção preciosa, e decididamente preferível a não existência, a saída dela não precisaria ser guardada por sentinelas tais como o medo da morte e de seus terrores. Mas quem iria viver a vida como ela é, se a morte fosse menos terrível? E quem poderia suportar o mero pensamento da morte, se a vida fosse um prazer? Mas a primeira tem sempre o lado bom de ser o fim da vida, e nós nos consolamos com a morte devido aos sofrimentos da vida, e com os sofrimentos da vida devido à morte ${ }^{27}$.

A terrível visão da morte nos faz permanecer na vida, a despeito de suas dores e do insuportável tédio, ao mesmo tempo em que a morte nos consola diante dos sofrimentos da vida. Também para Bernardo Soares, em uma interessante convergência, é incompreensível como se pode suportar este mal-estar de viver, este tédio radical, que somente sabemos que suportamos por que ainda persistimos na vida.

Há dias em que sobre em mim, como que da terra alheia à cabeça própria, um tédio, uma mágoa, uma angústia de viver que só me não parece insuportável porque de fato a suporto. É um estrangulamento da vida em mim mesmo, um desejo de ser outra pessoa em todos os poros, uma breve notícia do fim ${ }^{28}$.

O relato de Bernardo Soares sugere que seria melhor ser outra pessoa, na esperança de que este indivíduo pudesse não ser como ele é, pudesse não sentir o mundo como ele o sente. Ainda que seja uma expectativa impossível, pois não há como escapar do que se é, vislumbra-se aqui a possibilidade de que outras pessoas não sintam tal sofrimento advindo do encontro radical com o tédio.

Neste aspecto, observa-se uma dissonância em relação a Schopenhauer que, ao propor a uma decifração metafísica do mundo, acaba por enfatizar que não há por que querer ser outro, pois todos nós somos submetidos a esta mesma condição, que é a própria à essência do mundo. Não há termo final para o sofrimento, seja ele dor ou tédio.

\footnotetext{
${ }^{27}$ SCHOPENHAUER, MVR II, Cap. XLVI, Vol.2, p.303.

${ }^{28}$ PESSOA, Livro do Desassossego, p.200.
} 
A metafísica imanente de Schopenhauer oferece-nos uma leitura acerca do mundo pela qual estar vivo significa "ser vontade" e, portanto, estar condicionado a ser o que se é. Em outras palavras: não é possível escapar a condição que nos é própria, não há algo que se possa fazer ou lugar para onde ir, sempre seremos apenas o que somos. $\mathrm{O}$ caos que desde sempre já somos e a vacuidade de nossas existências, revela-se no tédio que nos atormenta inevitavelmente. Tal experiência pode ser muito bem ilustrada nas palavras de Bernardo Soares:

O tédio é a sensação física do caos, e de que o caos é tudo. O aborrecido, o mal-estante, o cansado sentem-se presos numa cela estreita. O desgostoso da estreiteza da vida sente-se algemado numa cela grande. Mas o que tem tédio sente-se preso em liberdade frusta numa cela infinita. Sobre o que se aborrece, ou tem mal-estar, ou fadiga, podem desabar os muros da cela, e soterrá-lo. Ao que se desgosta da pequenez do mundo, podem cair as algemas, e ele fugir; ou doer de as não poder tirar, e ele, com sentir a dor, reviver-se sem desgosto. Mas os muros da cela infinita não nos podem soterrar, porque não existem; nem nos podem sequer fazer viver pela dor as algemas que ninguém nos pôs ${ }^{29}$.

Esta alegoria - estar preso em uma cela infinita... - pode nos convidar a pensar com profundidade sobre a experiência do tédio tal como fundamentada filosoficamente por Schopenhauer: "a existência em si mesma não tem nenhum valor, pois o tédio nada mais é que o sentimento de sua vacuidade" ${ }^{30}$.

Por fim, vale ainda considerar outro aspecto que se destaca também a título de possível convergência: o papel da experiência estética. Como se sabe, para Schopenhauer, a contemplação estética, se faz por um desligamento momentâneo da servidão do intelecto em relação à vontade. Tal experiência se caracteriza por uma contemplação objetiva da Ideia por um sujeito cognoscente liberto da vontade individual. O indivíduo que conhece - suas mazelas, preocupações ou conflitos -, bem como o objeto particular que é conhecido - suas possíveis utilidades ou proveitos para a vontade -, não interessam de modo algum a esse sujeito puro, tornam-se, portanto, absolutamente estranhas a ele. Pode-se dizer que contemplação estética é uma experiência de libertação em relação ao sujeito empírico, pois aquele que contempla é

\footnotetext{
${ }^{29}$ PESSOA, Livro do Desassossego, p.203, meus grifos.

${ }^{30}$ SCHOPENHAUER, P/P, § 146, pp.141-142.
} 


\title{
LEANDRO CHEVITARESE
}

apenas sujeito puro do conhecimento, livre de toda dor e tédio. E diante disso, seria convidativo perguntar se tal coisa não se faz presente poeticamente nas palavras de Bernardo Soares:

\begin{abstract}
Escrevo isso sob a opressão de um tédio que parece não caber em mim, ou precisar de mais que da minha alma para ter onde estar; de uma opressão de todos e de tudo que me estrangula e desvaira; de um sentimento físico da incompreensão alheia que me perturba e esmaga. Mas ergo a cabeça para o céu azul alheio, exponho a face ao vento inconscientemente fresco, baixo as pálpebras depois de ter visto, esqueço a face depois de ter sentido. Não fico melhor, mas fico diferente. Ver-me liberta-me de mim. Quase sorrio, não porque me compreenda, mas porque, tendo-me tornado outro, me deixei de poder compreender. No alto do céu, como uma nada visível, uma nuvem pequeníssima é um esquecimento branco do universo inteiro ${ }^{31}$.
\end{abstract}

Para Schopenhauer, o sofrimento existencial, o tédio absurdo advindo de confrontar-se com a vacuidade da vida poderia ser superado, ainda que momentaneamente, pela experiência estética. E o filósofo ainda poderia acrescentar: somente a experiência estética e a compaixão poderiam redimir a falta de sentido do mundo, o absurdo de existir, o mal-estar de viver, enfim, tais experiências poderiam redimir o tédio de viver.

Para além disso, a outra via que se oferece, como se sabe, é a completa Negação da Vontade de Viver. Mas isso é para poucos...

\section{Referências bibliográficas}

PESSOA, F. Livro do Desassossego, por Bernardo Soares. SP: Ed. Brasiliense, 1986.

RAYMOND, D. Schopenhauer. Écrivains de toujours. Paris: Éditions du Seuil, 1979.

SCHOPENHAUER, A. Die Welt als Wille und Vorstellung. In: Sämmtliche Werke. Textkritisch bearbeitet und herausgegeben von Wolfgang Frhr. von Löhneysen. Frankfurt am Main: Suhrkamp, 1986.

O Mundo como Vontade e como Representação. Tomo I. Trad. Jair Barboza. SP: UNESP, 2005.

\footnotetext{
${ }^{31}$ PESSOA, Livro do Desassossego, pp.201-202, meus grifos. 
Revista Voluntas: Estudos sobre Schopenhauer - Vol. 5, № 2 - 2º semestre de 2014 - ISSN: 2179-3786 - pp. 21-33.

O Mundo como Vontade e Representação. Tomo II. Complementos. Trad. Eduardo Fonseca. Vols. I e II. Curitiba: Ed. UFPR, 2014.

Parerga and Paralipomena. Trad. E. F. J. Payne. Vols. I e II. New York: Oxford University Press, 2000.

Aforismos para a sabedoria de vida. Trad. Jair Barboza. SP: Martins Fontes, 2002.

Sobre a Ética. [Textos de Parerga e Paralipomena] Trad. Flamarion Ramos. SP: Hedra, 2012.

Recebido: 30/12/14

Received: $12 / 30 / 14$

Aprovado: $10 / 02 / 15$

Approved: 02/10/15 